\title{
Interleukin-8 and its receptor CXCR2 in the tumour microenvironment promote colon cancer growth, progression and metastasis
}

\section{YS Lee ${ }^{1,2}$, I Choi ${ }^{1,2}$, Y Ning ${ }^{2,3}$, NY Kim ${ }^{1,2}$, V Khatchadourian ${ }^{1,2}$, D Yang ${ }^{2,4}$, HK Chung ${ }^{1,2}$, D Choi ${ }^{1,2}$, MJ LaBonte, ${ }^{2,3}$, RD Ladner ${ }^{2,5}$, KC Nagulapalli Venkata ${ }^{6}$, DO Rosenberg ${ }^{6}$, NA Petasis ${ }^{2,6}$, H-J Lenz ${ }^{2,3}$ and Y-K Hong ${ }^{*, 1,2}$}

'Department of Surgery, Biochemistry and Molecular Biology, University of Southern California, 1450 Biggy Street NRT650I, Los Angeles, CA 90033, USA; ${ }^{2}$ Norris Comprehensive Cancer Center, Keck School of Medicine, University of Southern California, Los Angeles, CA, USA; ${ }^{3}$ Division of Medical Oncology, University of Southern California, Los Angeles, CA, USA; ${ }^{4}$ Department of Preventive Medicine, University of Southern California, Los Angeles, CA, USA; ${ }^{5}$ Department of Pathology, University of Southern California, Los Angeles, CA, USA; ${ }^{6}$ Department of Chemistry, Dornsife College of Letters, Arts and Sciences, University of Southern California, Los Angeles, CA, USA

BACKGROUND: Colorectal cancer (CRC) is a leading cause of death in the United States. Increased level of interleukin-8 (IL-8) and CXCR2 on tumours and in the tumour microenvironment has been associated with CRC growth, progression and recurrence in patients. Here, we aimed to evaluate the effects of tissue microenvironment-encoded IL-8 and CXCR2 on colon cancer progression and metastasis.

METHODS: A novel immunodeficient, skin-specific IL-8-expressing transgenic model was generated to evaluate colon cancer growth and metastasis. Syngeneic mouse colon cancer cells were grafted in CXCR2 knockout (KO) mice to study the contribution of CXCR2 in the microenvironment to cancer growth.

RESULTS: Elevated levels of IL-8 in the serum and tumour microenvironment profoundly enhanced the growth of human and mouse colon cancer cells with increased peri-tumoural angiogenesis, and also promoted the extravasation of the cancer cells into the lung and liver. The tumour growth was inhibited in CXCR2 KO mice with significantly reduced tumour angiogenesis and increased tumour necrosis. CONCLUSION: Increased expression of IL-8 in the tumour microenvironment enhanced colon cancer growth and metastasis. Moreover, the absence of its receptor CXCR2 in the tumour microenvironment prevented colon cancer cell growth. Together, our study demonstrates the critical roles of the tumour microenvironment-encoded IL-8/CXCR2 in colon cancer pathogenesis, validating the pathway as an important therapeutic target.

British Journal of Cancer (2012) I06, 1833-184I. doi:I0.1038/bjc.2012.177 www.bjcancer.com

(c) 2012 Cancer Research UK

Keywords: colorectal cancer; CXCR2; IL-8; tumour microenvironment

Colorectal cancer (CRC) is the third most common cancer and also the leading cause of death from gastrointestinal malignancy in the United States. Colorectal cancer ranks second after lung cancer in death rates in the United States (Siegel et al, 2011). Studies suggest that chemokines and their receptors serve as important regulators of various metastatic and advanced cancers (Coussens and Werb, 2001; Coussens and Werb, 2002). Among them, interleukin-8 (IL-8) and its receptor CXCR2 are two of the most significantly upregulated chemokines in colon cancer (Chen et al, 2004). The role of IL- 8 and CXCR2 in tumour development and progression has been well documented in a wide range cancer cells (Brat et al, 2005; Singh et al, 2006; Araki et al, 2007; Yao et al, 2007; Merritt et al, 2008; Waugh and Wilson, 2008; Singh et al, 2009). Expression and secretion of IL-8 by tumour cells enhance proliferation and survival of the cells through autocrine activation, and promote angiogenesis and neutrophil infiltration into the tumour. The

*Correspondence: Dr Y-K Hong; E-mail: young.hong@usc.edu Received 16 January 20 I2; revised 29 March 20 I2; accepted I April 2012 proangiogenic effects of IL-8 have been shown to be independent from its chemotactic activity for neutrophils and other pro-inflammatory effects (Strieter et al, 1992; Hu et al, 1993; Li et al, 2003). The IL-8/CXCR2-mediated autocrine properties have been demonstrated to activate the intrinsic mechanism of tumour cells to evade stress-induced apoptosis (Maxwell et al, 2007). Therefore, tumour cell-derived IL-8 can exert profound effects on tumour growth, survival, invasion, angiogenesis, metastases, resistance and recurrence. Nonetheless, studies on the effects of tumour microenvironment-encoded IL- 8 and CXCR2 are rather limited, mostly due to the intuitive speculation for the equivalent roles regardless of their sources.

Importantly, a common single-nucleotide polymorphism (SNP) in IL-8 at -251 bp (251-bp upstream of the IL-8 transcription start site) has been associated with increased plasma levels of IL-8 (Hull et al, 2000) and with IL-8 promoter activities (Lee et al, 2005; Ohyauchi et al, 2005). This allele has recently been correlated with an increased risk of developing breast, prostate and gastric cancers (McCarron et al, 2002; Taguchi et al, 2005; Snoussi et al, 2006). $\mathrm{We}$ - for the first time - demonstrated that this IL-8T - 251A 
polymorphism was individually associated with risk of tumour recurrence (Gordon et al, 2006). Moreover, our classification and regression tree analyses of CRC produced a classification tree with node status and four marker genes (IL-8, intracellular adhesion molecule-1, transforming growth factor- $\beta$ and fibroblast growth factor receptor-4) (Gordon et al, 2006). Our genotyping study of 12 biomarker genes in 125 patients with advanced CRC found that patients with vascular endothelial growth factor (VEGF) $+936 \mathrm{C} / \mathrm{C}$ and IL-8 $-251 \mathrm{~A} / \mathrm{A}$ genotype were at the greatest risk to develop tumour recurrence (Lurje et al, 2008), suggesting that polymorphisms in VEGF and IL-8 may serve as a key biomarker to identify stage III CRC patients who are at a great risk for tumour recurrence. In a separate study (Schultheis et al, 2008), we identified statistically significant four polymorphisms in CXCR2 and VEGF and demonstrated that the IL-8A - 251T polymorphism may be a molecular predictor of response to anti-VEGF chemotherapy. The CXCR2 C+785T and VEGF C+936T SNPs can be used as molecular markers for progression-free survival (PFS) in cancer patients. Together, the polymorphisms and expression of IL-8 and CXCR2 are strongly associated with not only tumour progression, but also tumour recurrence and oxaliplatin chemoresistance in patients with various cancers, including CRC (Gordon et al, 2006; Lurje et al, 2008; Schultheis et al, 2008; Zhang et al, 2009).

We have recently reported that IL-8 regulates proliferation, migration, angiogenesis and chemosensitivity in vitro and in vivo in colon cancer models (Ning et al, 2011). In addition, our clinical data showed that patients with stage IV CRC display more than 10 times higher serum level of IL-8 (1089 $\left.\mathrm{pg} \mathrm{ml}^{-1} \pm 311\right)$, compared with individuals with no evidence of disease $\left(79 \mathrm{pg} \mathrm{ml}^{-1} \pm 56\right)$ (Ning et al, 2011). In the current study, we tested whether the in-vivo tissue microenvironment with either elevated IL-8 or CXCR2 deletion will promote colon cancer growth, invasion and metastases using a novel IL-8 transgenic mouse model and a CXCR2 knockout (KO) model. Our findings using these mouse models demonstrate the critical roles of IL-8/CXCR2 in the tumour environment, which is highly cohesive with our numerous previous experimental and clinical data, and further indicates that IL- 8 and CXCR2 may be an important therapeutic target against colon cancer.

\section{MATERIALS AND METHODS}

\section{Cell lines and animals}

A mouse colon carcinoma cell line CT26 (BALB/c background) and a human colon cancer cell line HCT116 were purchased from American Type Culture Collection (ATCC, Manassas, VA, USA) and grown in RPMI plus $10 \%$ calf serum and DMEM plus $10 \%$ calf serum, respectively. HCT116 cells stably expressing the firefly luciferase and red fluorescent protein (RFP), named HCT116LR, were generated by transducing HCT116 with a lentivirus co-expressing the luciferase and RFP (Amsbio, Lake Forest, CA, USA), and the transduced cells were pooled and cultured for further studies. All animal studies were approved by the University of Southern California Institutional Animal Care and Use Committee. The keratin-14-based hIL- 8 transgenic mouse line (K14-hIL-8) was generated by the USC Transgenic Animal Core by pronuclear injection of a keratin-14promoter-driven hIL-8 expression cassette, which was made by cloning a PCR-amplified $0.3-\mathrm{kb}$ hIL-8 open reading frame fragment into a BamHI of the keratin-14 expression vector (Vassar et al, 1989) (kindly provided by Dr Elaine Fuchs, The Rockefeller University). The founders, with B6D2 background, were screened for the expression of hIL-8 in their serum and one founder was chosen to establish a line. To transfer the K14-hIL-8 transgene to an immunodeficient mouse background, K14-hIL-8 mice were bred with athymic nude mice (Crl:NU-Foxn $1^{n u}$ ) from Charles River Laboratories International, Inc. (Wilmington,
MA, USA). Nude mice with hemizygote K14-hIL-8 transgene were screened for based on PCR (5'-GGCCCAGCAGGCAGCCCAAG- $3^{\prime} /$ $5^{\prime}$-AGGGATCTCCTCAAAGGCTTC-3'), followed by digestion with $B s e \mathrm{DI}$ and used for human colon cancer cell xenograft studies. CXCR2 $\mathrm{KO}$ mice in BALB/c background (C.129S2(B6)-Cxcr2 $\left.{ }^{\text {tmlMwm}} / \mathrm{J}\right)$ were purchased from the Jackson Laboratory (Bar Harbor, MN, USA).

\section{In-vivo tumour growth study}

One million CT26 cells in $100 \mu$ l phosphate-buffered saline (PBS) were injected into both the right and left flanks of wild-type (WT) control and CXCR2 KO mice (six mice per group). Two hundred and thousand CT26 cells in $100 \mu \mathrm{l}$ PBS were injected into the right and left flanks of WT control and K14-hIL-8/nude mice (seven mice per group). One million of HCT116 cells in $100 \mu \mathrm{l}$ PBS were injected into both flanks of WT control and K14-hIL-8/nude mice (five mice per group). Each tumour volume was measured by width $(\mathrm{mm})$ and length $(\mathrm{mm})$ every 2 days using a digital caliper $(0.1 \mathrm{~mm}$ increments) until they were killed. Tumour volumes were calculated with the following formula: tumour volume $=$ $\left(\left(\right.\right.$ width $^{2} \times$ length $\left.) / 2\right)$.

\section{Delayed-type hypersensitivity reactions}

As previously described (Kunstfeld et al, 2004), 2\% oxazolone (4-ethoxymethylene-2 phenyl-2-oxazoline-5-one; Sigma, St Louis, MO, USA) solution in acetone/olive oil ( $4: 1 \mathrm{vol} / \mathrm{vol})$ was treated topically onto the shaved abdomens $(50 \mu \mathrm{l})$ and onto each paw $(5 \mu \mathrm{l})$ of 6 - to 8 -week-old mice, which did not display pre-existing inflammatory lesions. After 5 days, $20 \mu \mathrm{l}$ of a $1 \%$ oxazolone solution was challenged on their right ears and the vehicle was treated on the left ears. The ear thickness (total nine mice per time point) was measured up to 16 days until swellings were all reduced.

\section{Metastasis assay}

One million HCT116LR cells were injected into the tail veins of the control WT and K14-hIL-8/nu mice (five mice per group). Mice were killed after 15 weeks for analyses. Non-invasive images of whole mice and then their organs (liver, lung, heart, spleen, kidney and subcutaneous lesions) were captured to detect luciferase and RFP signals by Molecular Imaging Center (University of Southern California), as previously described (Bhaumik and Gambhir, 2002; Wang and El-Deiry, 2003; Paroo et al, 2004). The total number of metastatic foci was counted and compared between the WT and K14-hIL-8/nu mice.

\section{Immunohistochemistry and vascular analyses}

At the end of study, tumour samples were harvested and processed for paraffin embedding. Anti-CD31 (AbCam, San Francisco, CA, USA; $1: 1000$ ) and hIL-8 (BioLegend, San Diego, CA, USA; $1: 200$ ) antibodies were used for IHC. Immunohistochemistry images were captured using AxioImager Z1 microscope (Zeiss, Oberkochen, Germany) and vascular analyses were performed using the NIH ImageJ software (Bethesda, MD, USA).

\section{RNA isolation and semi-quantitative RT-PCR}

TRIzol Reagent (Sigma) was used to extract total RNAs from mouse skin. In all, $2 \mu \mathrm{g}$ of tissue RNA was subjected to the standard RT-PCR procedures. The expression of mouse GAPDH was also detected as an internal control for normalisation. Primer sequences will be provided upon request.

\section{Cell proliferation assay and ELISA}

Cell proliferation was determined by increased cell number using the WST-1 assay kit (Fisher, Pittsburgh, PA, USA). In brief, cells were grown in a low serum media (DMEM plus $1 \%$ fetal bovine 
serum) in the presence of DMSO (0.1\%; Sigma), hIL-8 (10 $\mathrm{ng} \mathrm{ml}^{-1}$; $\mathrm{R} \& \mathrm{D}$, Minneapolis, MN, USA), mouse Gro- $\alpha$ (10 $\mathrm{ng} \mathrm{ml}^{-1}$; Peprotech, Rocky Hill, NJ, USA) and/or SCH-527123 (synthesised by Dr Nicos Petasis). After $48 \mathrm{~h}$, the cultures were treated with WST-1 for $3 \mathrm{~h}$ and then their absorbance was measured at $450 \mathrm{~nm}$. For the ELISA, whole blood was collected from mouse tails and, after coagulation, centrifuged to obtain the serum. Serum levels of hIL-8 was determined using Human IL-8 ELISA development kit from BioLegend.

\section{Statistical analyses}

The outcome measures are expressed as the mean \pm s.d. per experimental condition. Analysis of variance or a $t$-test was used to detect the differences in outcome measures across conditions for all in-vitro and in-vivo experiments. A mixed linear model with the autoregressive covariance structure overtime was used to compare tumour volume for the duration of the experiment by condition. The analyses were conducted using the SAS statistical package version 9.2 (SAS Institute Inc., Cary, NC, USA). Two-sided $P$-values were reported for all tests at a significance level of 0.05 .

\section{RESULT}

The IL-8 and CXCR2 signalling stimulate the proliferation of the CT26 and HCT116 colon cancer cells

To study the effect of the IL-8/CXCR2 signal on colon cancer cells, we chose the mouse colon carcinoma cell line CT26 and human CRC cell line HCT116. We first confirmed the expression of CXCR2 in the two cell lines by immunofluorescence (IF) staining (Figure 1A and C). The IF analyses without the anti-CXCR2 antibody failed to exhibit any signal, validating the specificity of the antibody for CXCR2 (Figure $1 \mathrm{~B}$ and $\mathrm{D}$ ). We then studied the proliferative responses of these two cancer cell lines to IL-8. Indeed, the addition of hIL-8 was able to stimulate cell proliferation of both the mouse and human colon cancer cells (Figure $1 \mathrm{E}$ and F). Next, a selective antagonist for CXCR1/2, SCH527123 (Dwyer et al, 2006; Chapman et al, 2007), was used to confirm that the IL-8-activated cell proliferation was mediated through CXCR2, and further that $\mathrm{SCH}-527123$, in the presence of IL-8, inhibits the proliferation of both cell lines (Figure $1 \mathrm{G}$ and H).

Generation and characterisation of a transgenic mouse line with a targeted expression of hIL-8 in the skin

In order to develop an animal model, in which IL-8 was steadily supplied by the tumour microenvironment, we generated a noble transgenic mouse (K14-hIL-8) that can express and secret hIL-8 from the skin. The K14-hIL-8 mouse carries a transgene cassette that contains the hIL- 8 open reading frame under the direction of the basal keratinocyte-specific keratin-14 promoter (Figure 2A). A combined analyses using enzyme-linked immunosorbent assay (ELISA) and PCR-based genotyping showed that $>100 \mathrm{pg} \mathrm{ml}^{-1}$ of hIL-8 was detectable in the serum from the founder mice that carried the transgene cassette (Figure 2A). In addition, IHC analyses confirmed that hIL- 8 was abundantly produced in the keratinocytes of the skin and diffused towards the subcutaneous area in the K14-hIL-8, but not in the WT nude mice (Figure 2B and $\mathrm{C}$ ). In addition to these expression studies, we performed a functional assay to validate the activity of hIL- 8 produced and secreted by the mouse skin cells. Since the IL-8/CXCR2 pathway has been known to play a major role in inflammation, we carried out the delayed-type hypersensitivity (DTH) assay, which allows us to assess the contribution of hIL-8 produced by mouse keratinocytes to cell-based inflammatory response. Ears of the WT and K14-hIL-8 transgenic mice were subjected to the Oxazolone-based DTH reaction and the thickness of the ears, an indicator of the severity of inflammatory responses, was measured every day thereafter. Indeed, while the vehicle-treated ears remained unchanged, Oxazolone-challenged ears developed severe swellings from day 1 in both genotypes of mice (Figure 2D). Importantly, however, the K14-hIL-8 transgenic mice exhibited a significant increase in ear swelling over the WT mice did during the first week. This finding indicates that the mouse keratinocyte-encoded hIL-8 in the transgenic mice was fully functional and could augment the DTH-induced inflammatory responses. Together, our novel K14-hIL-8 transgenic mice may serve as a useful animal model to create a tissue microenvironment with increased IL-8 expression.

\section{Increased IL-8 levels in the tumour microenvironment promoted tumour growth and enhanced angiogenesis}

We next set out to investigate the establishment of xenograft tumour formation and subsequent growth of mouse CT26 and human HCT116 colon cancer cells in the K14-hIL-8 transgenic mice. A potential limitation to this experiment was the possibility that when implanted into the K14-hIL-8 transgenic mice (B6D2 background), CT26 (BALB/c background) and HCT116 (human) cells may elicit immune responses, which will significantly influence tumour formation and growth as well as tumourassociated angiogenesis. To address this, we established immunodeficient K14-hIL-8 transgenic mouse line by crossing the K14hIL-8 mice with athymic immunodeficient nude mice.

The immunodeficient K14-hIL-8 transgenic mouse model, termed K14-hIL-8/nu, was then used to investigate the impact of elevated IL-8 levels in tissue microenvironment on the formation and growth of mouse and human colon cancers. One million CT26 colon cancer cells were subcutaneously injected into either the K14-hIL-8/nu mice or non-transgenic WT nude mice. Importantly, the CT26 tumours in the K14-hIL-8/nu mice grew much faster when compared with those in the nude control mice (Figure 3A). Morphometric analyses of CD31-positive vessels revealed an increased vessel number in the peri-tumour area, but not within the tumour, of the K14-hIL-8/nu mice (Figure 3B). In addition, an increased vessel number in both peri-tumoural and intra-tumoural regions was detected in the K14-hIL-8/nu mice (Figure 3C).

Similarly, one million HCT116 cells were subcutaneously injected into the flanks of both K14-hIL-8/nu and WT nude mice. Consistent with CT26 experiment, HCT116 cells in the K14-hIL-8/ nu mice established tumours earlier and the resulting tumours grew much faster when compared with the WT nude mice (Figure 3D). In addition, vascular analyses revealed a statistically significant increase in CD31-positive vessel number only in the peri-tumoural area, but not in the intra-tumoural region (Figure 3E). We did not find any statistically significant changes in the microvascular density (Figure 3F). Importantly, no changes in the vessel number in the intra-tumoural area between these two mouse groups was observed, in noteworthy contrast to the significant vessel number increase by tumour cell-derived IL-8, as our recent study showed (Ning et al, 2011). This suggests that the IL-8 supplied by the tumour microenvironment activates angiogenesis predominantly in the peri-tumoural area rather than the intra-tumoural region.

\section{Enhanced metastatic potential of human colon cancer cells in animal models with increased serum levels of IL-8}

Because our previous clinical data showed that patients with metastatic CRC exhibit $>10$ times higher serum levels of IL-8 when compared with normal individuals (Ning et al, 2011), we next studied the impact of increased serum IL-8 levels on the metastatic potential of HCT116 cells. In particular, we aimed to assess the ability of HCT116 colon cancer cells to extravasate into distant organs and then to establish metastatic foci and secondary 
A

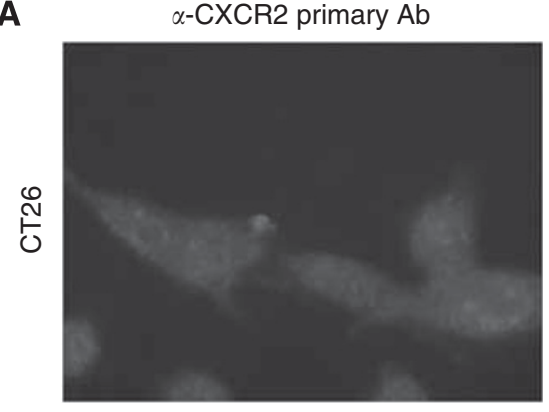

C

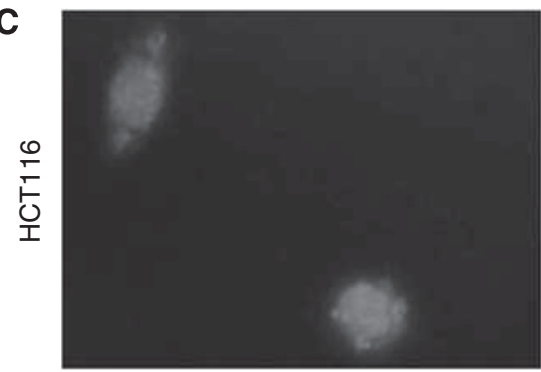

E

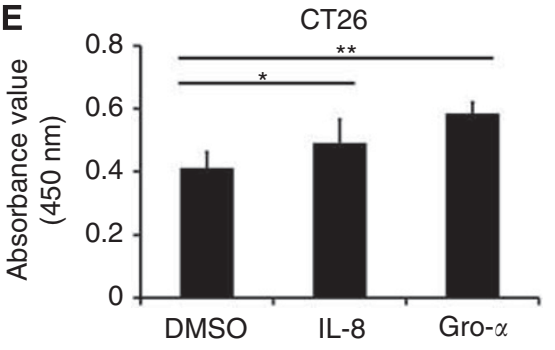

G

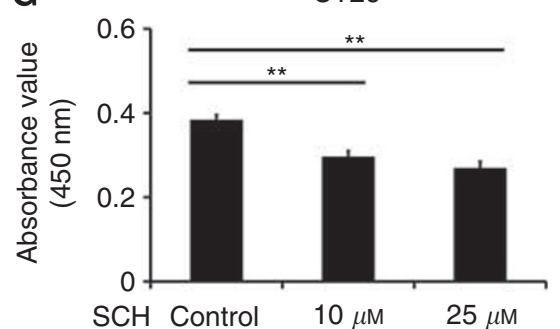

B

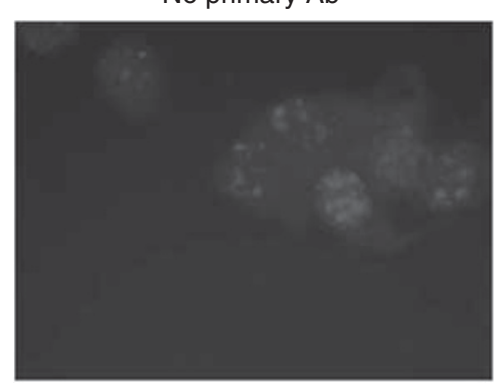

D

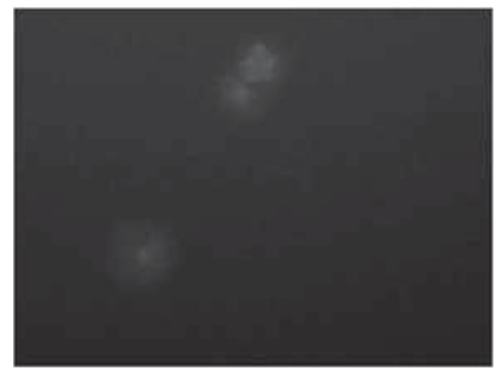

$\mathbf{F}$

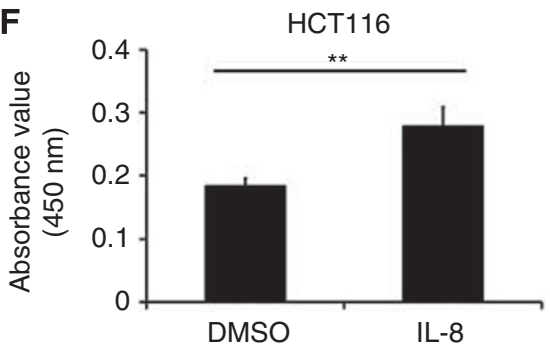

$\mathbf{H}$

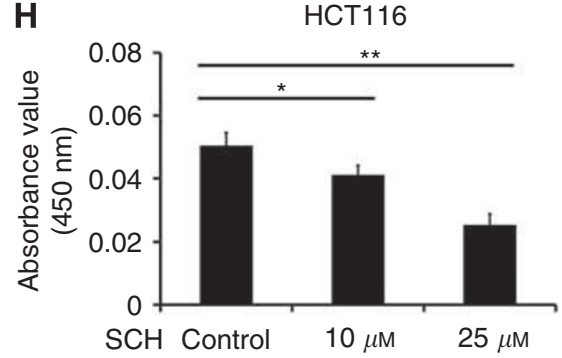

Figure I Proliferation of CT26 and HCTII 6 cancer cells was activated by the IL-8 and CXCR2 pathway. (A-D) IF images of CXCR2 on CT26 (A) and HCTII6 (C) cancer cell lines. The same IF assays were performed without the primary antibody to confirm the specificity of the primary antibody for CXCR2 (B, D). Bar, $20 \mu \mathrm{m}$. (E, F) Proliferation assays were performed on CT26 (E) or HCTI I6 (F) cells in a low serum (I\%) media containing vehicle (DMSO), hlL-8 $\left(10 \mathrm{ng} \mathrm{ml}^{-1}\right)$ or Gro- $\alpha\left(10 \mathrm{ng} \mathrm{ml}^{-1}\right)$. (G, H) The CXCR2 antagonist, SCH-527I23, efficiently blocked the IL-8-induced activation of cell proliferation. Proliferation assay was performed with vehicle (DMSO), or IL-8 $\left(10 \mathrm{ng} \mathrm{ml}^{-1}\right)$ in the presence of SCH-527 I $23(\mathrm{I} 0$ or $25 \mu \mathrm{M})$ on CT26 (G) and HCTII6 (H) cells. SCH, SCH-527I23. Data are expressed as mean \pm s.d.; $* P<0.05$; $* * P<0.005$.

tumours. We engineered HCT116 cells to stably express both firefly luciferase and RFP by lentivirus transduction (Figure 4A). These labelled HCT116 cells (HCT116LR) were injected into the tail veins of K14-hIL-8/nu or WT nude mice. After 7 weeks, both the whole mice and individual organs were subjected to bioluminescent/fluorescent imaging analyses (Figure 4B-D). Micrometastatic foci and secondary tumours were counted in two major metastatic lesions sites (the lung and liver) and other organs of K14-hIL-8/nu or WT nude mice. It was indeed found that the HCT116LR colon cancer cells had an increased metastatic potential in the K14-hIL-8/nu mice when compared with the WT nude mice (total incidence: 4.2 vs $0.75, P<0.05$ ) (Figure 4E).

\section{Both colon cancer growth and angiogenesis was inhibited by CXCR2 deletion in the tumour microenvironment}

Interleukin- 8 is known to bind to and active the high affinity receptor, CXCR2. Previous studies showed delayed wound healing and reduced lung cancer growth in CXCR2 KO mice (Devalaraja et al, 2000; Keane et al, 2004). More recently, CXCR2 inhibition was found to disrupt tumour-stromal interactions and also improve survival in a pancreatic ductal adenocarcinoma mouse model (Ijichi et al, 2011). We have reported that a CXCR2 polymorphism may be served as a molecular marker for PFS in ovarian cancer patients (Schultheis et al, 2008). Moreover, we also reported another CXCR2 polymorphism that can predict clinical 

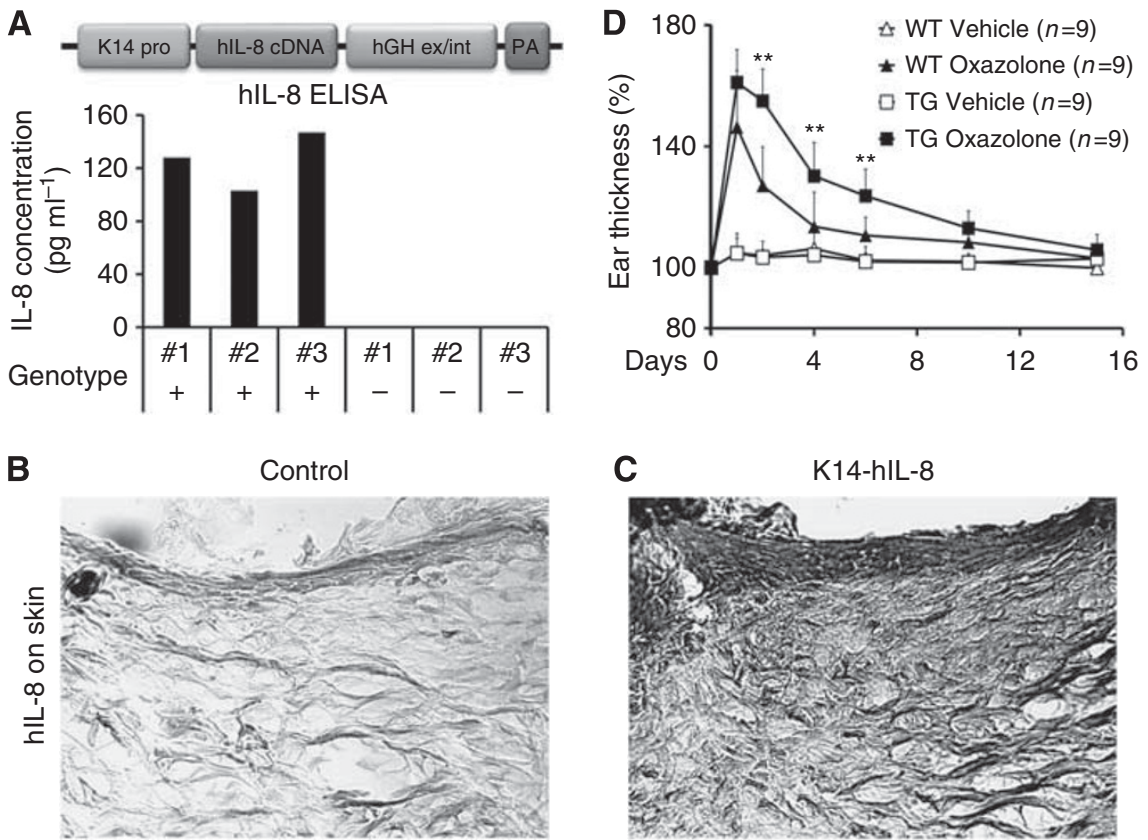

Figure 2 Generation and characterisation of a transgenic mouse model producing functional hlL-8 in the skin. (A) The upper image represents a transgene construct used to generate the KI4-hIL-8 transgenic mice. KI4 pro, Keratin-I4 promoter; hGH ex/int, human growth hormone exons/introns; PA, poly A. The lower graph shows the serum level of hIL-8 protein in different founder mice determined by ELISA, which is consistent with the PCR-based genotyping results. (B, C) IHC analyses detecting hIL-8 in the skin of the WT control (B) vs KI4-hlL-8 transgenic (C) mice. (D) DTH reactions were induced in the right ear of WT and KI4-hIL-8 transgenic (TG) mice using Oxazolone. Left ears of both groups were treated with vehicle alone as a negative control to set the base line. Data are expressed as an average per cent thickness \pm s.d. (nine mice per group). Note more prominent swelling was detected in the ears of the TG mice than those of WT mice during the first week. After I 6 days, the swelling was largely resolved in both groups. $* P<0.05$; $* * P<0.005$.
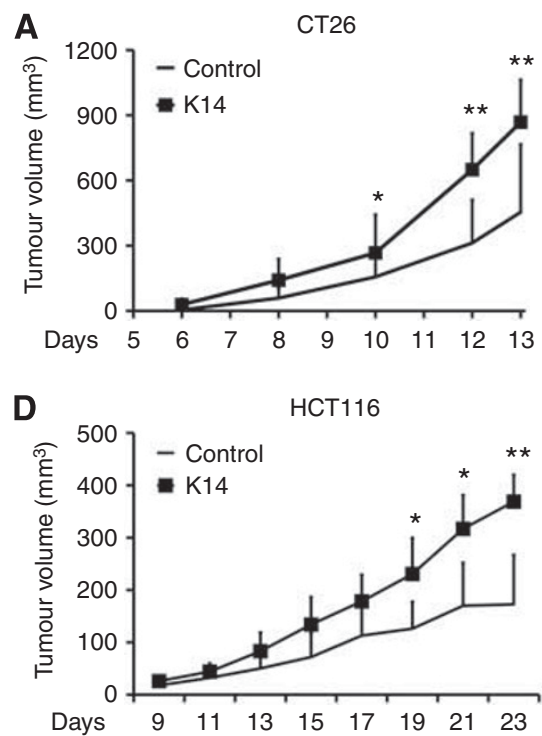
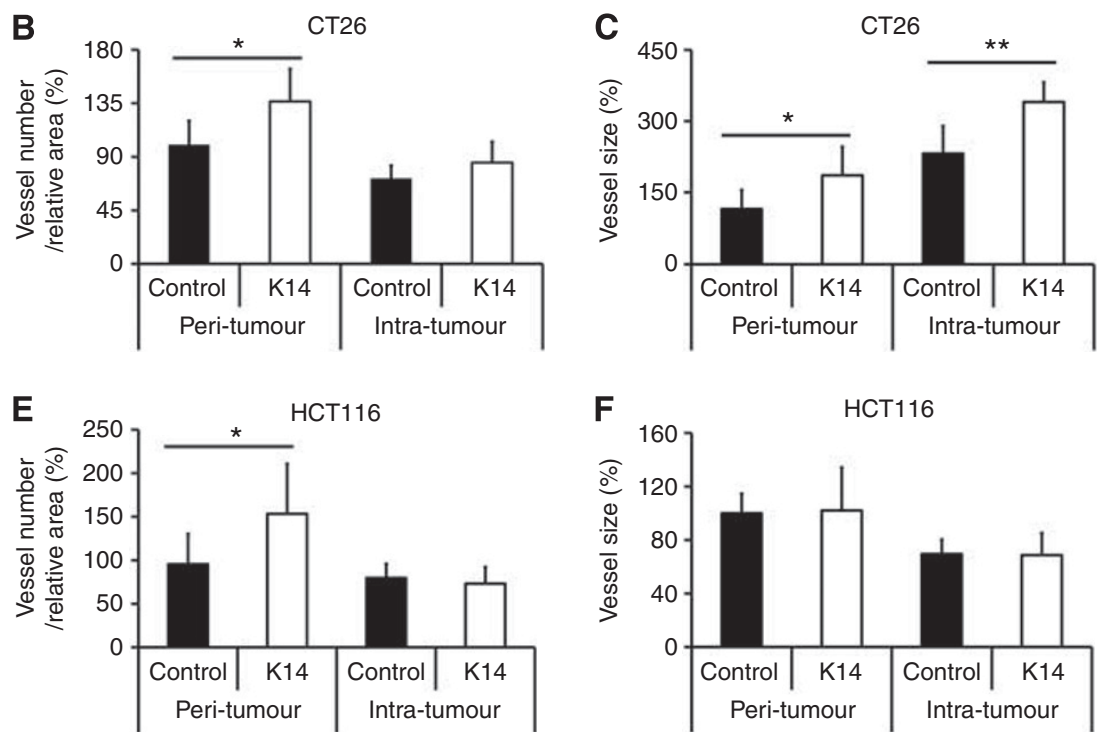

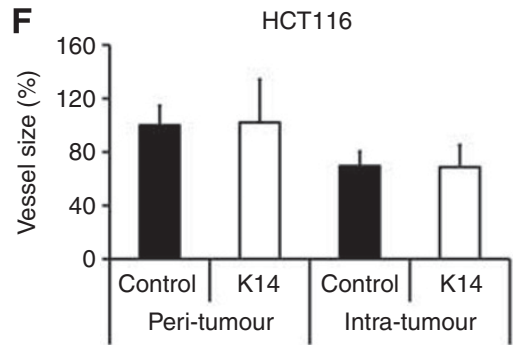

Figure 3 Enhanced tumour growth in the KI4-hlL-8/nu mouse with increased peri-tumoural angiogenesis (A) One million CT26 cells were subcutaneously injected into the left and right flank of the KI4-hIL-8/nu $(n=10)$ or WT nude mice $(n=10)$ and tumour volume was measured every 2 days for 2 weeks. Tumour size was expressed as an average \pm s.d. Number/area (B) and size $(\mathbf{C})$ of CD3I-positive vessels found in the peri-tumour ( $n=6)$ and intra-tumour areas $(n=6)$ were measured in both groups of tumour and displayed as an average \pm s.d. (D) One million HCTII 6 cells were subcutaneously injected into the left and right flank of the KI4-hIL-8/nu $(n=6)$ or WT nude mice $(n=4)$, and tumour volume was measured every 2 days for 23 days. Number/area $(\mathbf{E})$ and size $(\mathbf{F})$ of CD3I-positive vessels in the peri-tumoural $(n=8)$ and intra-tumoural areas $(n=6)$ were measured in both groups of tumour and displayed as an average \pm s.d. $* P<0.05$, $* * P<0.005$.

outcome and tumour response in metastatic CRC patients treated with bevacizumab and oxaliplatin-based chemotherapy (Gerger et al, 2011). Another germline polymorphism in CXCR2 was identified to play a pivotal role in the epidermal growth factor receptor pathway (Zhang et al, 2005).
Thus, we next determined the role of CXCR2 in the tumour microenvironment in colon cancer cell growth using syngeneic CXCR2 KO mice. Equal number of CT26 cells (BALB/c background) were subcutaneously injected into the left and right flanks of the WT or CXCR2 KO mice, both in the BALB/c background and 
A

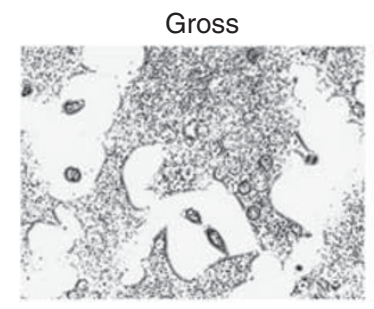

B

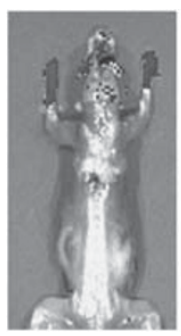

Control

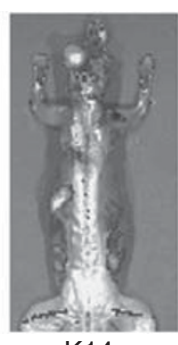

K14
D
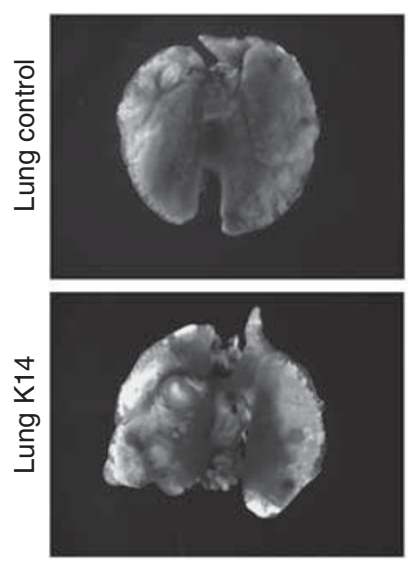

E

\begin{tabular}{|l|c|c|}
\hline $\begin{array}{c}\text { Foci } \\
\text { (ave.) }\end{array}$ & WT & K14 \\
\hline Lung & 0 & 2.2 \\
\hline Liver & 0.5 & 0.8 \\
\hline Etc. & 0.25 & 1.2 \\
\hline Total & 0.75 & 4.2 \\
\hline
\end{tabular}

RFP-labelled HCT116

RFP
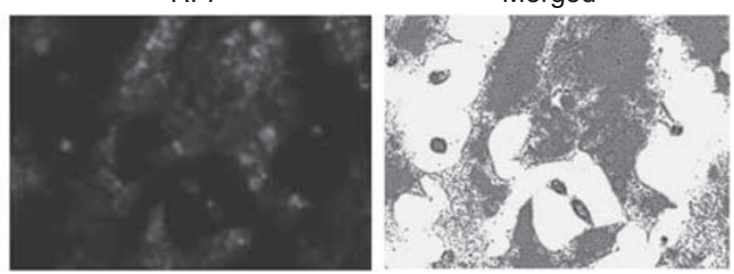

C
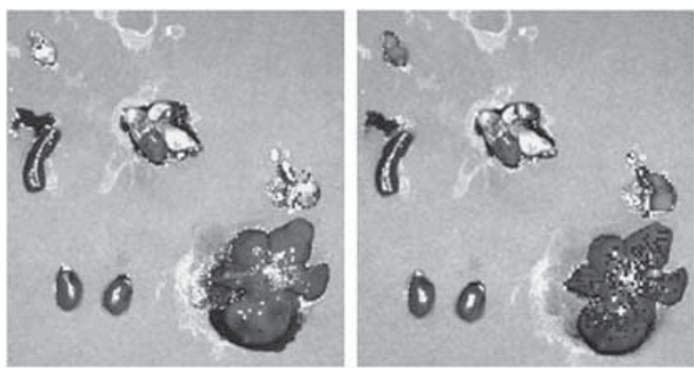

RFP
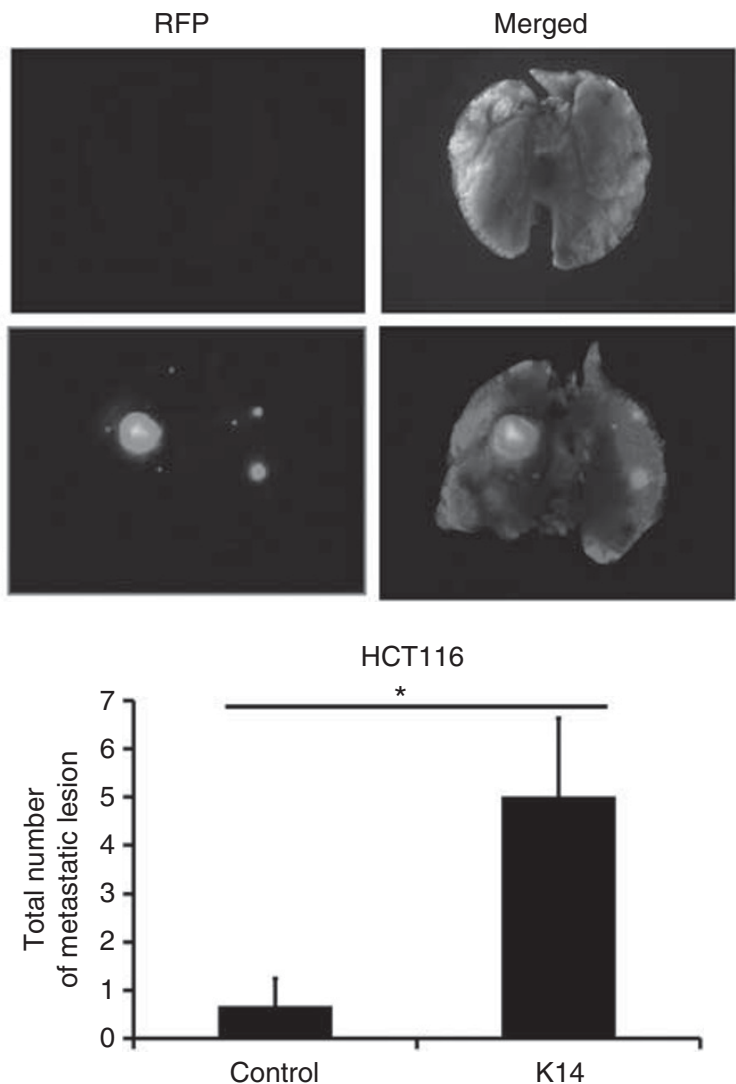

Figure 4 Enhanced metastatic potential of human colon cancer cells in KI4-hIL-8/nu mice (A) Bright field, red fluorescent and combined images of cultured HCTI I 6LR cells $(\times 100)$ (B) RFP signals from both WT nude and KI4-hlL-8/nu mouse. Both mice were skinned to better detect the RFP signal. (C) Liver, lung, heart, kidney, spleen and subcutaneous lesions were harvested from KI4-hIL-8/nu mice and their bioluminescent signals from firefly luciferase and fluorescent signals from RFP were simultaneously captured. (D) Bright field and red fluorescent images showing lung metastases in the WT nude and KI4-hIL-8/nu mice. (E) Average number of metastatic lesions in the lung, liver and other organs (skin, heart, spleen and kidney) in the WT nude ( $n=5$ ) and KI4-hIL-8/nu $(n=6)$ mice. Graph represents the average number of total metastases in the WT nude vs KI4-hIL-8/nu mice. * $P<0.05$. The colour reproduction of this figure is available at the British Journal of Cancer online.

tumour growth was measured for 15 days (Figure 5A). Notably, tumours in both groups of mice grew in a comparable rate until they reached a volume of $\sim 100 \mathrm{~mm}^{3}$. Thereafter, tumours in the WT mice grew faster than those in CXCR2 KO mice (Figure 5A). Vascular analyses revealed that tumours in the CXCR2 KO mice show a reduced average vessel number/area in the peri-tumoural region and a reduced average vessel size in the intra-tumoural area (Figure 5B, C and F). Moreover, we found increased necrotic area in tumours in the CXCR2 KO mice, compared with the WT mice (Figure 5D and E). A previous study has shown that depletion of 
A

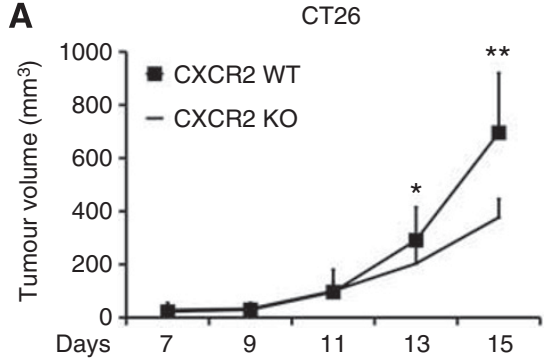

D

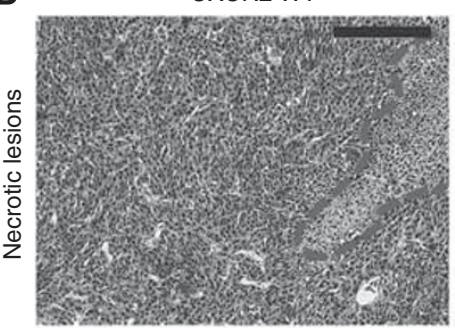

F

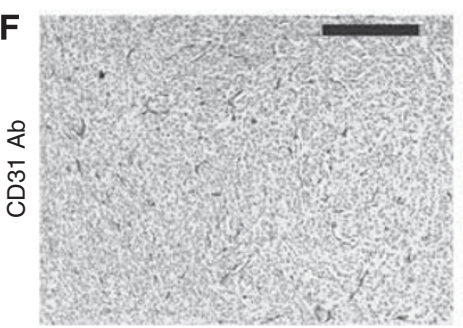

B

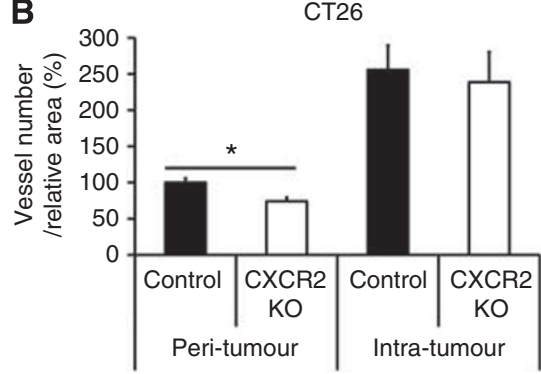

C

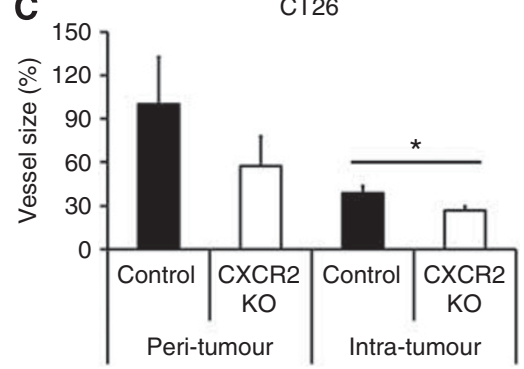

E

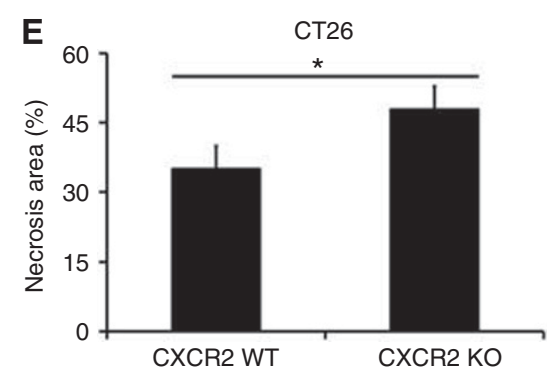

G

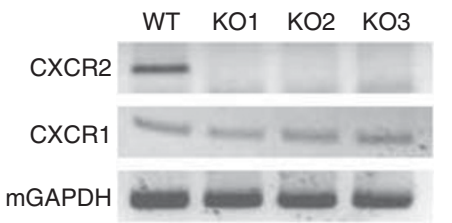

Figure 5 Expression of CXCR2 in the tumour microenvironment is required for optimal growth of colon cancer cells. (A) CT26 tumour growth in the WT and CXCR2 KO mice. One million CT26 cells were injected into the flanks of the WT $(n=10)$ and CXCR2 KO $(n=10)$ mice and tumour growth was measured every 2 days for 15 days. Number/area $(\mathbf{B})$ and size $(\mathbf{C})$ of CD3I-positive vessels found in the peri-tumoural and intra-tumoural areas were measured in both groups and displayed as an average \pm s.d. (D) Necrotic lesions (red dotted line) in CT26 tumours of the WT and CXCR2 KO mice are shown (H\&E staining). Bar, $200 \mu \mathrm{m}$. (E) Percentage of necrotic area in tumours in the WT vs CXCR2 KO mice. (F) IHC staining showing CD3I-positive vessels in the peri-tumoural areas in the WT vs CXCR2 KO mice. (G) Expression of CXCRI and CXCR2 was determined in the skin of the WT or three independent CXCR2 KO (KOI 3) mice by semi-quantitative conventional RT-PCR. $* P<0.05$; $* * P<0.005$. The colour reproduction of this figure is available at the British Joumal of Cancer online.

CXCR1 led to downregulation of CXCR2 at the transcription level without a reciprocal regulation of CXCR1 by CXCR2 (Shamaladevi et al, 2009). We examined the expression level of CXCR1 mRNA in the CXCR2 KO mice and confirmed the absence of regulation of CXCR1 by CXCR2 at least at the transcriptional level (Figure 5G). Taken together, our studies demonstrate that the deletion of CXCR2 in the tumour microenvironment profoundly affects colon cancer growth and accompanying development of angiogenesis, and further increases intra-tumoural necrosis, providing evidence of the essential roles of CXCR2 in colon cancer development and progression.

\section{DISCUSSION}

Colorectal cancer is the leading cause of death from gastrointestinal malignancy and second most common cause of cancer-related death in the United States. Interleukin-8 and its receptor, CXCR2, are significantly upregulated in various stages of CRC and their respective tissue microenvironments. From patient specimens acquired through translational and clinical trials, we have reported that genetic variations in IL- 8 and CXCR2 genes profoundly affects CRC progression, drug sensitivity and tumour recurrence (Gordon et al, 2006; Lurje et al, 2008; Schultheis et al, 2008; Zhang et al, 2009). This capacity to determine clinical outcomes highlights the evolving role of IL-8/CXCR2 as the molecular predictors of response, in particular with regards to patient responsiveness towards anti-VEGF and oxaliplatin-based chemotherapy (Zhang et al, 2003, 2005, 2006; Vallbohmer et al, 2005; Gordon et al, 2006; Lurje et al, 2008). We have also identified that IL-8 may serve as a key factor capable of promoting CRC proliferation and progression by stimulating tumour cell proliferation, invasion, migration and angiogenesis (Ning et al, 2011).

Our data using novel animal models demonstrate for the first time that the expression of IL-8/CXCR2 in the tumour microenvironment plays a critical role in colon cancer growth, progression and metastases. We and others previously had shown that polymorphisms in the IL-8/CXCR2 genes that elevates serum levels of IL-8 were associated with colon cancer progression, recurrence and drug resistance (Hull et al, 2000; McCarron et al, 2002; Lee et al, 2005; Ohyauchi et al, 2005; Taguchi et al, 2005; Gordon et al, 2006; Snoussi et al, 2006; Lurje et al, 2008; Schultheis et al, 2008; Zhang et al, 2009; Ning et al, 2011). Importantly, we have recently reported that tumour cell-derived IL-8 promotes colon cancer growth in vitro and in vivo and that advanced colon cancer patients exhibit 10 times higher serum levels of IL-8 when compared with normal individuals (Ning et al, 2011). However, these studies suggest that the regulation of IL- 8 within the tumour and microenvironment play a critical role, but the impact of tissue microenvironment-derived IL- 8 and CXCR2 to date has been difficult to evaluate.

In this study, we investigated the effect of increased expression of IL-8 in the tumour microenvironment on colon cancer growth by generating a novel immunodeficient, transgenic mouse 
(K14-hIL-8/nu) that expresses hIL-8 in the skin. Human and mouse colon cancer cells were seeded in the IL-8-rich tissue environment of the K14-hIL-8/nu skin and their tumour formation and growth were studied. Both human and mouse colon cancer cells were found to form tumours with increased volume in the IL-8-rich tissue environment when compared with the normal tissue environment. Interestingly, IL-8 supplied from the tumour microenvironment stimulated the peri-tumoural, but not intratumoural, angiogenesis, unlike tumour cell-derived IL-8, which activated angiogenesis in the entire tumour area (Ning et al, 2011). Moreover, the increased serum expression of IL-8 was also found to enhance cancer cell extravasation into the lung and liver tissue and growth of secondary tumours therein. This finding is particularly important in the context of our previous finding of an increased serum levels of IL-8 in patients with metastatic CRC (Ning et al, 2011), which suggests that the systemic increase of IL-8 may be more important for the prognosis than the local, tumour cell-derived IL- 8 levels. Moreover, our study with the CXCR2 KO mouse model further supports the profound role of the microenvironment-derived IL-8/CXCR2 in colon cancer growth. In addition to IL-8, CXCR2 can be activated by other cytokines such as Gro- $\alpha /$ CXCL1, which has been also adversely associated with colon cancer development and progression (Cuenca et al, 1992; Baier et al, 2005; Wen et al, 2006; Ogata et al, 2010). Therefore, our current studies verify utilising two mouse models the previously speculated, but not yet proven role that the microenvironmentderived IL-8 and CXCR2 play in colon cancer growth and metastasis.

Importantly, activated IL-8/CXCR2 in colon cancer confers a resistance to the anti-VEGF therapy: IL-8 maintains its

\section{REFERENCES}

Araki S, Omori Y, Lyn D, Singh RK, Meinbach DM, Sandman Y, Lokeshwar VB, Lokeshwar BL (2007) Interleukin-8 is a molecular determinant of androgen independence and progression in prostate cancer. Cancer Res 67(14): 6854-6862

Baier PK, Eggstein S, Wolff-Vorbeck G, Baumgartner U, Hopt UT (2005) Chemokines in human colorectal carcinoma. Anticancer Res 25(5): 3581-3584

Bhaumik S, Gambhir SS (2002) Optical imaging of Renilla luciferase reporter gene expression in living mice. Proc Natl Acad Sci USA 99(1): 377-382

Brat DJ, Bellail AC, Van Meir EG (2005) The role of interleukin-8 and its receptors in gliomagenesis and tumoral angiogenesis. Neuro Oncol 7(2): $122-133$

Chapman RW, Minnicozzi M, Celly CS, Phillips JE, Kung TT, Hipkin RW, Fan X, Rindgen D, Deno G, Bond R, Gonsiorek W, Billah MM, Fine JS, Hey JA (2007) A novel, orally active CXCR1/2 receptor antagonist, Sch527123, inhibits neutrophil recruitment, mucus production, and goblet cell hyperplasia in animal models of pulmonary inflammation. J Pharmacol Exp Ther 322(2): 486-493

Chen LC, Hao CY, Chiu YS, Wong P, Melnick JS, Brotman M, Moretto J, Mendes F, Smith AP, Bennington JL, Moore D, Lee NM (2004) Alteration of gene expression in normal-appearing colon mucosa of $\mathrm{APC}\left({ }_{\text {min }}\right)$ mice and human cancer patients. Cancer Res 64(10): 3694-3700

Coussens LM, Werb Z (2001) Inflammatory cells and cancer: think different! J Exp Med 193(6): F23-F26

Coussens LM, Werb Z (2002) Inflammation and cancer. Nature 420(6917): 860-867

Cuenca RE, Azizkhan RG, Haskill S (1992) Characterization of GRO alpha, beta and gamma expression in human colonic tumours: potential significance of cytokine involvement. Surg Oncol 1(4): 323-329

Devalaraja RM, Nanney LB, Du J, Qian Q, Yu Y, Devalaraja MN, Richmond A (2000) Delayed wound healing in CXCR2 knockout mice. J Invest Dermatol 115(2): 234-244

Dwyer MP, Yu Y, Chao J, Aki C, Biju P, Girijavallabhan V, Rindgen D, Bond R, Mayer-Ezel R, Jakway J, Hipkin RW, Fossetta J, Gonsiorek W, Bian H, Fan X, Terminelli C, Fine J, Lundell D, Merritt JR, Rokosz LL, Kaiser B, Li G, Wang W, Stauffer T, Ozgur L, Baldwin J, Taveras AG (2006) proangiogenic activity even in HIF1 $\alpha$-deficient colon cancer cells, where VEGF expression was compromised and IL-8 expression was significantly induced by production of hydrogen peroxide and subsequent activation of NF- $\kappa \mathrm{B}$ (Mizukami et al, 2005). This finding indicates that IL-8 plays a key role in tumour angiogenesis independent of VEGF, and operates even when VEGF is limited or inactivated, suggesting a mechanism underlying colon cancer resistance against anti-VEGF therapy (Mizukami et al, 2005). Moreover, the KRAS oncogene, which is frequently mutated in colon cancer, enhances the hypoxic induction of IL-8 and a neutralising antibody against IL-8 substantially inhibited angiogenesis and tumour growth (Mizukami et al, 2005). Taken together, the IL-8/CXCR2 signal pathway has been demonstrated to be a promising target for colon cancer since inhibition of this pathway may not only lead to antitumour properties, but may also chemosensitise the tumour toward the current chemotherapy.

\section{ACKNOWLEDGEMENTS}

This study was supported by American Cancer Society (YKH), NIH/NICHD (YKH), Daniel Butler Memorial Fund (HJL), Teri Lanni Research Fund (HJL) and American Chemical Society A. C. Cope Fund (NAP).

\section{Conflict of interest}

The authors declare no conflict of interest.
Discovery of 2-hydroxy-N,N-dimethyl-3-\{2-[[(R)-1-(5-methylfuran-2-yl) propyl]amino]-3,4-dioxocyclobut-1-enylamino\}benzamide (SCH 527123): a potent, orally bioavailable CXCR2/CXCR1 receptor antagonist. J Med Chem 49(26): 7603-7606

Gerger A, El-Khoueiry A, Zhang W, Yang D, Singh H, Bohanes P, Ning Y, Winder T, Labonte MJ, Wilson PM, Benhaim L, Paez D, El-Khoueiry R, Absenger G, Lenz HJ (2011) Pharmacogenetic angiogenesis profiling for first-line Bevacizumab plus oxaliplatin-based chemotherapy in patients with metastatic colorectal cancer. Clin Cancer Res 17(17): 5783-5792

Gordon MA, Gil J, Lu B, Zhang W, Yang D, Yun J, Schneider S, Groshen S, Iqbal S, Press OA, Rhodes K, Lenz HJ (2006) Genomic profiling associated with recurrence in patients with rectal cancer treated with chemoradiation. Pharmacogenomics 7(1): 67-88

Hu DE, Hori Y, Fan TP (1993) Interleukin-8 stimulates angiogenesis in rats. Inflammation 17(2): 135-143

Hull J, Thomson A, Kwiatkowski D (2000) Association of respiratory syncytial virus bronchiolitis with the interleukin 8 gene region in UK families. Thorax 55(12): 1023-1027

Ijichi H, Chytil A, Gorska AE, Aakre ME, Bierie B, Tada M, Mohri D, Miyabayashi K, Asaoka Y, Maeda S, Ikenoue T, Tateishi K, Wright CV, Koike K, Omata M, Moses HL (2011) Inhibiting Cxcr2 disrupts tumorstromal interactions and improves survival in a mouse model of pancreatic ductal adenocarcinoma. J Clin Invest 121(10): 4106-4117

Keane MP, Belperio JA, Xue YY, Burdick MD, Strieter RM (2004) Depletion of CXCR2 inhibits tumor growth and angiogenesis in a murine model of lung cancer. J Immunol 172(5): 2853-2860

Kunstfeld R, Hirakawa S, Hong YK, Schacht V, Lange-Asschenfeldt B, Velasco P, Lin C, Fiebiger E, Wei X, Wu Y, Hicklin D, Bohlen P, Detmar M (2004) Induction of cutaneous delayed-type hypersensitivity reactions in VEGF-A transgenic mice results in chronic skin inflammati on associated with persistent lymphatic hyperplasia. Blood 104(4): 1048-1057

Lee WP, Tai DI, Lan KH, Li AF, Hsu HC, Lin EJ, Lin YP, Sheu ML, Li CP, Chang FY, Chao Y, Yen SH, Lee SD (2005) The -251T allele of the interleukin-8 promoter is associated with increased risk of gastric carcinoma featuring diffuse-type histopathology in Chinese population. Clin Cancer Res 11(18): 6431-6441 
Li A, Dubey S, Varney ML, Dave BJ, Singh RK (2003) IL-8 directly enhanced endothelial cell survival, proliferation, and matrix metalloproteinases production and regulated angiogenesis. J Immunol 170(6): 3369-3376

Lurje G, Zhang W, Schultheis AM, Yang D, Groshen S, Hendifar AE, Husain H, Gordon MA, Nagashima F, Chang HM, Lenz HJ (2008) Polymorphisms in VEGF and IL-8 predict tumor recurrence in stage III colon cancer. Ann Oncol 19(10): 1734-1741

Maxwell PJ, Gallagher R, Seaton A, Wilson C, Scullin P, Pettigrew J, Stratford IJ, Williams KJ, Johnston PG, Waugh DJ (2007) HIF-1 and NF-kappaB-mediated upregulation of CXCR1 and CXCR2 expression promotes cell survival in hypoxic prostate cancer cells. Oncogene 26(52): 7333-7345

McCarron SL, Edwards S, Evans PR, Gibbs R, Dearnaley DP, Dowe A, Southgate C, Easton DF, Eeles RA, Howell WM (2002) Influence of cytokine gene polymorphisms on the development of prostate cancer. Cancer Res 62(12): 3369-3372

Merritt WM, Lin YG, Spannuth WA, Fletcher MS, Kamat AA, Han LY, Landen CN, Jennings N, De Geest K, Langley RR, Villares G, Sanguino A, Lutgendorf SK, Lopez-Berestein G, Bar-Eli MM, Sood AK (2008) Effect of interleukin-8 gene silencing with liposome-encapsulated small interfering RNA on ovarian cancer cell growth. J Natl Cancer Inst 100(5): 359-372

Mizukami Y, Jo WS, Duerr EM, Gala M, Li J, Zhang X, Zimmer MA, Iliopoulos O, Zukerberg LR, Kohgo Y, Lynch MP, Rueda BR, Chung DC (2005) Induction of interleukin-8 preserves the angiogenic response in HIF-1alpha-deficient colon cancer cells. Nat Med 11(9): 992-997

Ning Y, Manegold PC, Hong YK, Zhang W, Pohl A, Lurje G, Winder T, Yang D, LaBonte MJ, Wilson PM, Ladner RD, Lenz HJ (2011) Interleukin-8 is associated with proliferation, migration, angiogenesis and chemosensitivity in vitro and in vivo in colon cancer cell line models. Int J Cancer 128(9): 2038-2049

Ogata H, Sekikawa A, Yamagishi H, Ichikawa K, Tomita S, Imura J, Ito Y, Fujita M, Tsubaki M, Kato H, Fujimori T, Fukui H (2010) GROalpha promotes invasion of colorectal cancer cells. Oncol Rep 24(6): 1479-1486

Ohyauchi M, Imatani A, Yonechi M, Asano N, Miura A, Iijima K, Koike T, Sekine H, Ohara S, Shimosegawa T (2005) The polymorphism interleukin $8-251 \mathrm{~A} / \mathrm{T}$ influences the susceptibility of Helicobacter pylori related gastric diseases in the Japanese population. Gut 54(3): 330-335

Paroo Z, Bollinger RA, Braasch DA, Richer E, Corey DR, Antich PP, Mason RP (2004) Validating bioluminescence imaging as a highthroughput, quantitative modality for assessing tumor burden. Mol Imaging 3(2): 117-124

Schultheis AM, Lurje G, Rhodes KE, Zhang W, Yang D, Garcia AA, Morgan R, Gandara D, Scudder S, Oza A, Hirte H, Fleming G, Roman L, Lenz HJ (2008) Polymorphisms and clinical outcome in recurrent ovarian cancer treated with cyclophosphamide and bevacizumab. Clin Cancer Res 14(22): 7554-7563

Shamaladevi N, Lyn DA, Escudero DO, Lokeshwar BL (2009) CXC receptor-1 silencing inhibits androgen-independent prostate cancer. Cancer Res 69(21): 8265-8274

Siegel R, Ward E, Brawley O, Jemal A (2011) Cancer statistics, 2011: the impact of eliminating socioeconomic and racial disparities on premature cancer deaths. CA Cancer J Clin 61(4): 212-236

Singh B, Berry JA, Vincent LE, Lucci A (2006) Involvement of IL-8 in COX-2mediated bone metastases from breast cancer. J Surg Res 134(1): 44-51
Singh S, Varney M, Singh RK (2009) Host CXCR2-dependent regulation of melanoma growth, angiogenesis, and experimental lung metastasis. Cancer Res 69(2): 411-415

Snoussi K, Mahfoudh W, Bouaouina N, Ahmed SB, Helal AN, Chouchane L (2006) Genetic variation in IL-8 associated with increased risk and poor prognosis of breast carcinoma. Hum Immunol 67(1-2): 13-21

Strieter RM, Kunkel SL, Elner VM, Martonyi CL, Koch AE, Polverini PJ, Elner SG (1992) Interleukin-8. A corneal factor that induces neovascularization. Am J Pathol 141(6): 1279-1284

Taguchi A, Ohmiya N, Shirai K, Mabuchi N, Itoh A, Hirooka Y, Niwa Y, Goto $H$ (2005) Interleukin-8 promoter polymorphism increases the risk of atrophic gastritis and gastric cancer in Japan. Cancer Epidemiol Biomarkers Prev 14(11 Pt 1): 2487-2493

Vallbohmer D, Zhang W, Gordon M, Yang DY, Yun J, Press OA, Rhodes KE, Sherrod AE, Iqbal S, Danenberg KD, Groshen S, Lenz HJ (2005) Molecular determinants of cetuximab efficacy. J Clin Oncol 23(15): 3536-3544

Vassar R, Rosenberg M, Ross S, Tyner A, Fuchs E (1989) Tissue-specific and differentiation-specific expression of a human K14 keratin gene in transgenic mice. Proc Natl Acad Sci USA 86(5): 1563-1567

Wang W, El-Deiry WS (2003) Bioluminescent molecular imaging of endogenous and exogenous p53-mediated transcription in vitro and in vivo using an HCT116 human colon carcinoma xenograft model. Cancer Biol Ther 2(2): 196-202

Waugh DJ, Wilson C (2008) The interleukin-8 pathway in cancer. Clin Cancer Res 14(21): 6735-6741

Wen Y, Giardina SF, Hamming D, Greenman J, Zachariah E, Bacolod MD, Liu H, Shia J, Amenta PS, Barany F, Paty P, Gerald W, Notterman D (2006) GROalpha is highly expressed in adenocarcinoma of the colon and down-regulates fibulin-1. Clin Cancer Res 12(20 Part 1): 5951-5959

Yao C, Lin Y, Chua MS, Ye CS, Bi J, Li W, Zhu YF, Wang SM (2007) Interleukin-8 modulates growth and invasiveness of estrogen receptornegative breast cancer cells. Int J Cancer 121(9): 1949-1957

Zhang W, Dahlberg S, Yang D, Sandler A, Brahmer J, Schiller J, Carbone D, Johnson D, Lenz H (2009) Genetic variants in angiogenesis pathway associated with clinical outcome in NSCLC patients (pts) treated with bevacizumab in combination with carboplatin and paclitaxel: Subset pharmacogenetic analysis of ECOG 4599. Poster Discussion Proc ASCO 27: 8032

Zhang W, Gordon M, Press OA, Rhodes K, Vallbohmer D, Yang DY, Park D, Fazzone W, Schultheis A, Sherrod AE, Iqbal S, Groshen S, Lenz HJ (2006) Cyclin D1 and epidermal growth factor polymorphisms associated with survival in patients with advanced colorectal cancer treated with Cetuximab. Pharmacogenet Genomics 16(7): 475-483

Zhang W, Lu B, Gil J, Yang D, Groshen S, Lenz HJ (2003) Interleukin-8 (IL-8) promoter region gene polymorphism predicts pelvic recurrence after chemo-radiation in patients with rectal cancer. Int J Radiat Oncol Biol Phys 57(2): S382

Zhang W, Stoehlmacher J, Park DJ, Yang D, Borchard E, Gil J, Tsao-Wei DD, Yun J, Gordon M, Press OA, Rhodes K, Groshen S, Lenz HJ (2005) Gene polymorphisms of epidermal growth factor receptor and its downstream effector, interleukin-8, predict oxaliplatin efficacy in patients with advanced colorectal cancer. Clin Colorectal Cancer 5(2): $124-131$

This work is published under the standard license to publish agreement. After 12 months the work will become freely available and the license terms will switch to a Creative Commons Attribution-NonCommercial-Share Alike 3.0 Unported License. 